\title{
Laparoscopic Enucleation of Schwannoma Masquerading as a Leiomyoma
}

\author{
Howard S. Fan" ${ }^{\mathrm{a}, \mathrm{b}}$, Ahmed A. Rahman, \\ Michael L. Talbot ${ }^{\mathrm{a}}$
}

\begin{abstract}
We present a case, literature review, and video of a transabdominal laparoscopic enucleation of an esophageal schwannoma. A 53-yearold female with dysphagia was found to have a $23 \times 27 \mathrm{~mm}$ mass in the lower esophagus, which was initially diagnosed as a leiomyoma on endoscopic ultrasound without biopsy. At the time of her laparoscopic enucleation 12 months later, the lesion had grown to $60 \times 55 \times 30 \mathrm{~mm}$ and was excised with a full-thickness segment of the esophageal wall, with closure of the resulting defect over a bougie. Postoperatively, the patient's recovery was complicated by an esophageal leak which was successfully managed with endoscopic drainage. Esophageal schwannomas are rare esophageal lesions that have historically been treated with esophagectomy. Thoracoscopic or laparoscopic enucleations of smaller lesions have been more recently reported but larger lesions have usually required open surgery. Internally placed endoscopic drains have previously been shown to be a valid alternative to external drainage in patients with contained collections after resection surgery. They have the advantage of allowing patients to continue oral fluids during the recovery phase rather than relying on enteral or parenteral feeding. We propose that laparoscopic transabdominal enucleation of esophageal schwannoma with closure of the resulting full-thickness defect be considered as an organ and function sparing alternative for the management of large lower esophageal schwannomas. We further propose that contained leaks resulting from esophageal operations can successfully be managed with internal endoscopic drainage.
\end{abstract}

Keywords: Schwannoma; Laparoscopy

\section{Introduction}

Esophageal schwannomas are rare esophageal lesions that

\section{Manuscript submitted April 6, 2017, accepted April 24, 2017}

aDepartment of Surgery, University of New South Wales, St George Hospital, Kogarah, NSW 2217, Australia

${ }^{b}$ Corresponding Author: Howard S. Fan, Department of Surgery, University of New South Wales, St George Hospital, Kogarah, NSW 2217, Australia.

Email: howard.fan@unsw.edu.au

doi: https://doi.org/10.14740/jmc2823w have historically been treated with esophagectomy. Thoracoscopic or laparoscopic enucleations of smaller lesions have been more recently reported but larger lesions have usually required open surgery. We present a case, literature review, and video of a transabdominal laparoscopic enucleation of a $60 \times$ $55 \times 30 \mathrm{~mm}$ esophageal schwannoma which was initially diagnosed on endoscopic ultrasound as a leiomyoma.

\section{Case Report}

A 53-year-old female, with no significant medical history, presented to hospital for investigation of dysphagia. An endoscopy was performed with the initial endoscopic ultrasound without biopsy revealing a $23 \times 27 \mathrm{~mm}$ mass in the lower esophagus arising from the muscularis mucosa. This was diagnosed as a likely leiomyoma and the patient was booked on the waitlist for an elective laparoscopic enucleation on a 12 months priority. The patient had ongoing dysphagia but remained clinically well during this period.

At the time of transabdominal laparoscopic enucleation,

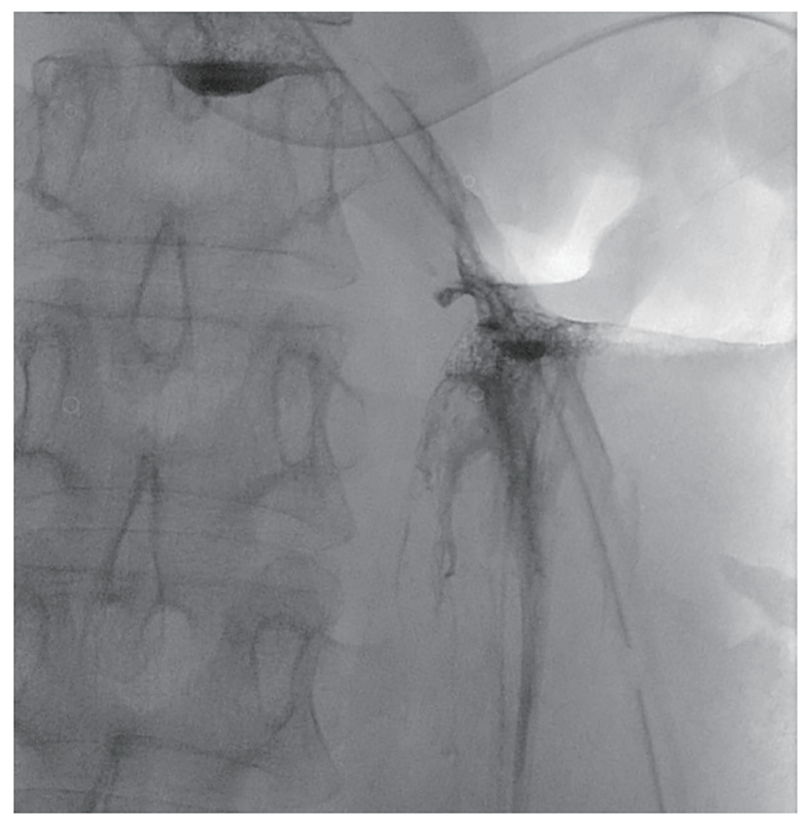

Figure 1. Gastrografin swallow series showing esophageal leak. 


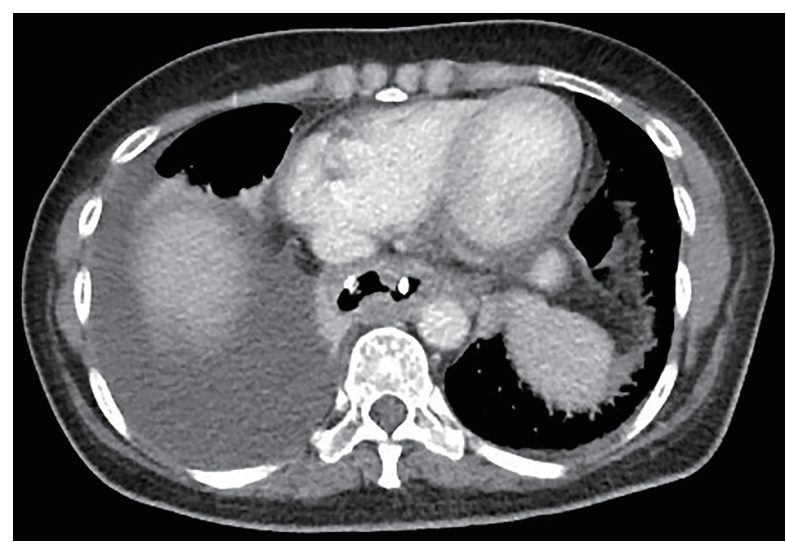

Figure 2. CT image, axial view, showing double $\mathrm{J}$ catheter in esophagus traversing through the defect with distal end in the paraesophageal collection.

the lesion had grown to $60 \times 55 \times 30 \mathrm{~mm}$, and a decision was made to continue with the planned procedure (Supplementary video 1, www.journalmc.org). While the tumor could be enucleated from the mediastinal structures, it could not be excised without creation of a $5 \mathrm{~cm}$ long mucosal defect. This defect was closed laparoscopically over on esophageal bougie and a surgical drain was placed. Postoperatively, the patient remained clinically well with stable blood chemistry and hematology result, apart from a raised C-reactive protein of 333 $\mathrm{mg} / \mathrm{L}$. An initial postoperative endoscopy did not reveal any abnormalities, and the patient was subsequently placed on oral feeds. In the following days oral feeds were observed in the external drains and an esophageal leak was confirmed on computed tomography (CT) and gastrografin swallow series (Fig. 1). The patient was initiated on bowel rest, intravenous antibiotics and taken back for endoscopy to manage the leak. The repeat endoscopy using a distal EMR cap to push the mucosa away provided a clearer image and revealed an esophageal defect at the apex of the suture-line. An internal $7 \times 7$ double $\mathrm{J}$ catheter was inserted through the defect via endoscopy. The external drain was subsequently removed and a repeat CT confirmed the endoscopically inserted drain in a satisfactory position with the distal end in the paraesophageal collection (Figs. 2 and 3). The patient was placed on a fluid diet the next day and completed $48 \mathrm{~h}$ of intravenous antibiotics before being discharged on day 3 on soft diet. She returned for endoscopic removal of drain at 7 weeks and has since remained well with no further complications.

\section{Discussion}

The most common benign intramural tumors of the esophagus are esophageal leiomyomas, which have an overall incidence of $0.1 \%$ and are typically located in the middle and lower thirds of the esophagus, and have historically been surgically managed through thoracotomy and enucleation of the lesion [1]. More recently, enucleation of esophageal tumors using minimally invasive thoracoscopic, laparoscopic and endoscopic techniques has been shown to be superior to open tech-

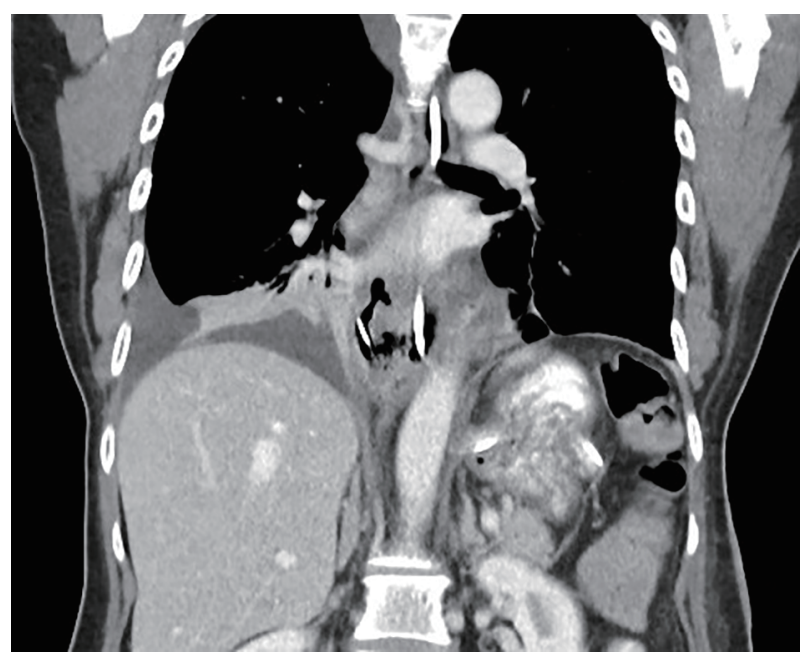

Figure 3. CT image, coronal view, showing double $\mathrm{J}$ catheter in esophagus traversing through the defect with distal end in the paraesophageal collection.

niques in terms of reducing postoperative hospital stay, with no difference in operative time, intraoperative complications, or recurrence [2].

Esophageal schwannomas are exceedingly rare with only a handful of cases reported in the literature [3]. A literature review performed for the past decade, 2005 - 2015, revealed a total of 21 cases of which two cases were of concurrent esophageal schwannomas [3-20]. The surgical approaches to these include four thoracoscopic, six thoracotomy, five cervical approaches, and five esophagectomies or partial esophagectomies. To the best of our knowledge, there were no reported cases treated by a transabdominal laparoscopic approach. Only two of the reported cases were of esophageal schwannomas in the lower esophagus and both were enucleated with thoracotomy approaches (Table 1) [3-20].

The management of postoperative esophageal leaks with endoscopically placed internal drains is a valid alternative to external drains as demonstrated by Talbot, Yee and Saxena (2015) who have successfully treated their patients with localized collections after esophagogastrectomies and gastrectomies with internal drainage [21]. They have the advantage of allowing patients to continue oral fluids during the recovery phase rather than relying on enteral or parenteral feeding. Our use of internal drainage in preference to external drainage of this patient allowed for easier drainage management and an earlier discharge from hospital.

\section{Conclusion}

We propose that laparoscopic transabdominal enucleation of esophageal schwannomas with closure of the resulting fullthickness defect be considered as an organ and function sparing alternative for the management of large lower esophageal schwannomas. We further propose that contained leaks resulting from esophageal operations can successfully be managed 
Table 1. Existing Literature on Schwannoma Size, Location and Surgical Approach for Removal of the Lesion [3-20]

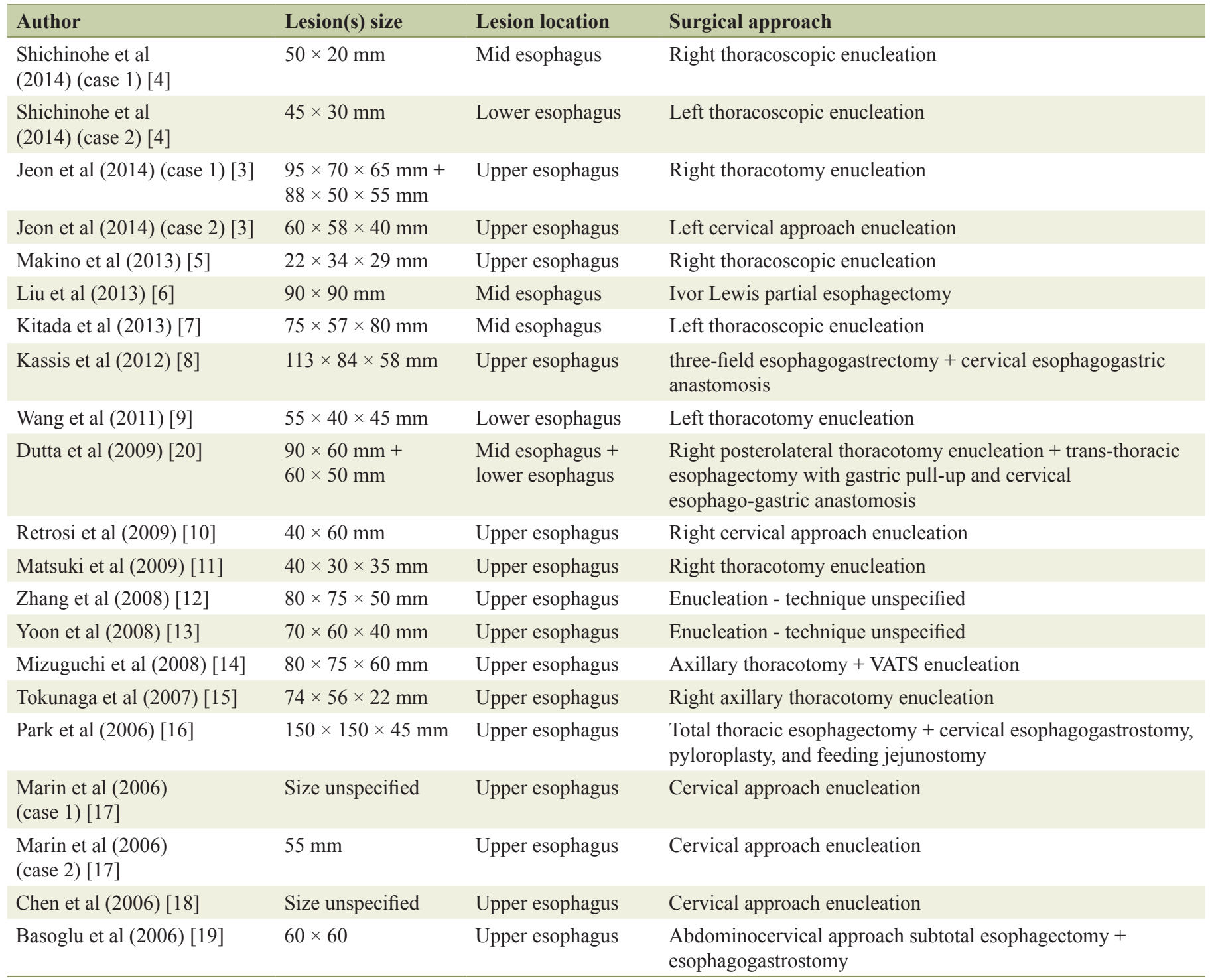

with internal endoscopic drainage.

\section{References}

1. Mutrie CJ, Donahue DM, Wain JC, Wright CD, Gaissert HA, Grillo HC, Mathisen DJ, et al. Esophageal leiomyoma: a 40-year experience. Ann Thorac Surg. 2005;79(4):1122-1125.

2. von Rahden BH, Stein HJ, Feussner H, Siewert JR. Enucleation of submucosal tumors of the esophagus: minimally invasive versus open approach. Surg Endosc. 2004;18(6):924-930.

3. Jeon HW, Kim KS, Hyun KY, Park JK. Enucleation of giant esophageal schwannoma of the upper thoracic esophagus: reports of two cases. World J Surg Oncol. 2014;12:39.
4. Shichinohe T, Kato K, Ebihara Y, Kurashima Y, Tsuchikawa T, Matsumoto J, Nakamura T, et al. Thoracoscopic enucleation of esophageal submucosal tumor by prone position under artificial pneumothorax by $\mathrm{CO} 2$ insufflation. Surg Laparosc Endosc Percutan Tech. 2014;24(2):e5558.

5. Makino T, Yamasaki M, Takeno A, Kurokawa Y, Miyata $\mathrm{H}$, Takiguchi S, Nakajima K, et al. Thoracoscopic enucleation of esophageal schwannoma exhibiting (18) Ffluorodeoxyglucose uptake on positron emission tomography. Dis Esophagus. 2013;26(3):331-332.

6. Liu T, Liu H, Yang C, Zhang X, Xu S, Liu B. Benign esophageal schwannoma compressing the trachea requiring esophagectomy: a case report. Thorac Cardiovasc Surg. 2013;61(6):505-506.

7. Kitada M, Matsuda Y, Hayashi S, Ishibashi K, Oikawa K, Miyokawa N. Esophageal schwannoma: a case report. 
World J Surg Oncol. 2013;11:253.

8. Kassis ES, Bansal S, Perrino C, Walker JP, Hitchcock C, Ross P, Jr., Daniel VC. Giant asymptomatic primary esophageal schwannoma. Ann Thorac Surg. 2012;93(4):e81-83.

9. Wang S, Zheng J, Ruan Z, Huang H, Yang Z, Zheng J. Long-term survival in a rare case of malignant esophageal schwannoma cured by surgical excision. Ann Thorac Surg. 2011;92(1):357-358.

10. Retrosi G, Nanni L, Ricci R, Manzoni C, Pintus C. Plexiform schwannoma of the esophagus in a child with neurofibromatosis type 2. J Pediatr Surg. 2009;44(7):14581461.

11. Matsuki A, Kosugi S, Kanda T, Komukai S, Ohashi M, Umezu H, Mashima Y, et al. Schwannoma of the esophagus: a case exhibiting high $18 \mathrm{~F}$-fluorodeoxyglucose uptake in positron emission tomography imaging. Dis Esophagus. 2009;22(4):E6-E10.

12. Zhang W, Xue X, Zhou Q. Benign esophageal schwannoma. South Med J. 2008;101(4):450-451.

13. Yoon HY, Kim CB, Lee YH, Kim HG. An obstructing large schwannoma in the esophagus. J Gastrointest Surg. 2008;12(4):761-763.

14. Mizuguchi S, Inoue K, Imagawa A, Kitano Y, Kameyama $\mathrm{M}$, Ueda H, Inoue Y. Benign esophageal schwannoma compressing the trachea in pregnancy. Ann Thorac Surg. 2008;85(2):660-662.

15. Tokunaga T, Takeda S, Sumimura J, Maeda H. Esophageal schwannoma: report of a case. Surg Today. 2007;37(6):500-502 .

16. Park BJ, Carrasquillo J, Bains MS, Flores RM. Giant benign esophageal schwannoma requiring esophagectomy. Ann Thorac Surg. 2006;82(1):340-342.

17. Marin VP, Yu P, Weber RS. Isolated cervical esophageal reconstruction for rare esophageal tumors. Head Neck. 2006;28(9):856-860.

18. Chen HC, Huang HJ, Wu CY, Lin TS, Fang HY. Esophageal schwannoma with tracheal compression. Thorac Cardiovasc Surg. 2006;54(8):555-558.

19. Basoglu A, Celik B, Sengul TA, Yildiz L. Esophageal schwannoma. J Thorac Cardiovasc Surg. 2006;131(2):492493.

20. Dutta R, Kumar A, Jindal T, Tanveer N. Concurrent benign schwannoma of oesophagus and posterior mediastinum. Interact Cardiovasc Thorac Surg. 2009;9(6):10321034.

21. Talbot M, Yee G, Saxena P. Endoscopic modalities for upper gastrointestinal leaks, fistulae and perforations. ANZ J Surg. 2017;87(3):171-176. 